\title{
Demographic variability indicators of somatically healthy men from different administrative and territorial regions of Ukraine
}

\author{
Volodymyr Mishalov ${ }^{1}$, Larisa Klimas ${ }^{2}$, Valery Gunas ${ }^{2 *}$
}

\begin{abstract}
${ }^{1}$ National Medical Academy of Postgraduate Education named after P.L. Shupyk, Dorohozhytska 9, Kyiv, 04112, Ukraine
${ }^{2}$ Department of Pathologic Anatomy, Forensic Medicine and Law, Vinnitsa National Medical University named after M.I. Pirogov, Pyrogov 56, Vinnytsia, 21018, Ukraine
\end{abstract}

\begin{tabular}{|c|c|}
\hline ARTICLE INFO & ABSTRACT \\
\hline $\begin{array}{l}\text { Received } 07 \text { March } 2016 \\
\text { Accepted } 01 \text { April } 2016\end{array}$ & \multirow[b]{3}{*}{$\begin{array}{l}\text { Our work has revealed a rather low level of similarity in regard to the finger dermatoglyphics } \\
\text { of somatically healthy men, 19-35 years old, between Ukraine's north and west, north and } \\
\text { south, center and west, center and south, as well as the palmar dermatoglyphics between } \\
\text { central regions and the east, center and west, center and south. The obtained finger/ } \\
\text { palmar dermatoglyphics did not differentiate administrative-territorial local groups of } \\
\text { men between the north and the center, south and west (quantitative characteristics); or } \\
\text { palmar - between the north and west, north and east, south and west, south and east, } \\
\text { north and center. The differences between the administrative and territorial division of } \\
\text { dermatoglyphic signs are a reflection of the historical and cultural differences induced } \\
\text { by migration, as well as the intensive process of mixing, in addition to the isolation of } \\
\text { particular groups. }\end{array}$} \\
\hline Accepted 01 April 2016 & \\
\hline $\begin{array}{l}\text { Keywords: } \\
\text { dermatoglyphics, } \\
\text { male, } \\
\text { administrative-territorial } \\
\text { regions of Ukraine. }\end{array}$ & \\
\hline
\end{tabular}

\section{INTRODUCTION}

The contemporary anthropological composition of the Ukrainian nation, the formation and development of which occurred in the area of contact of groups with different anthropological identity, is a reflection of the complex multi-vector ethnogenetical processes that took place in its ethnic territory during the last thousands of years. Anthropological data are an important source of historical information that allows researchers to reconstruct certain aspects of the ethnogenetical processes that occurred in the past [5]. In regard to this issue, the skin relief of human races and populations is, without any exaggeration, an effective means of enabling such reconstruction [2]. This system of dermatoglyphics signs is what I.G. Shyrobokov [7] calls an efficient tool for analyzing the anthropological composition of populations, and for identifying components of that which took part in their formation. G.L. Khyt and others [4] deem this a capacitive information system and an independent source of genetic information. They hold that discerning the differences in the frequency of traits in populations of different ranks (from local samples to large races) can solve the problem of determining the modern degree of genetic

\footnotetext{
* Corresponding author

e-mail: freekozak1@gmail.com

phone: 068-2121622
}

relationship, as well as the differences between human community taxonomic units of different rank [4].

The purpose of our research was to identify the distributive features of dermatoglyphic signs in somatically healthy males, aged 19-35 years, in different administrative-territorial regions of Ukraine.

\section{MATERIAL AND METHODS}

In this study, we examined the database of the Pirogov Scientific and Research Center, Vinnitsa National Medical University (Ukraine) for the dermatoglyphic primary indicators of 410 healthy men, aged 19 to 35 , who were third generation residents of the respective regions of Ukraine: 72 - from the north, 47 - from the south, 165 - from central, 71 - from the west, 45 residents of the eastern regions. The central administrative-territorial region included Vinnitsa, Cherkassy, Kirovograd, Poltava and Dnipropetrov; the south - Odessa, Mykolaiv, Kherson, Zaporizhzhya region and Crimea; east - Kharkov, Lugansk, Donetsk region; north - Zhitomir, Kyiv, Chernihiv and the Sumy region. Our research was conducted by way of analyzing the contained data of the selected sample-population for information regarding health and social conditions [6].

To accomplish this goal, we employed the following methods: dermatoglyphic study performed through utilizing 
the method of H. Cummins and Ch. Midlo [1]; fingerprints and hand prints obtained through employing printing ink on a sheet of paper [3]; statistical analysis of the results conducted through using the package «STATISTICA 6.1», and through the application of nonparametric methods.

In undertaking this work, the Center's Committee on Bioethics, Vinnitsa National Medical University found that our study is not contrary to the fundamental bioethical norms of the Helsinki Declaration, the European Convention on Human Rights and Biomedicine (1977), the relevant provisions of the WHO and the laws of Ukraine (Minutes № 8 from 10.09.2013).

\section{RESULTS AND DISCUSSION}

The results of our study indicate the presence of dermatoglyphics signs of intra population variability. Our work indicates that most of the differences in registered finger dermatoglyphic characteristics was found between the north $\leftrightarrow$ west (11 signs), north $\leftrightarrow$ south (13 signs), center $\leftrightarrow$ west (13 signs), center $\leftrightarrow$ south (12 signs); between regions south $\leftrightarrow$ east (10 signs), center $\leftrightarrow$ east (10 signs). However, practically no differences were evident between the regions: north $\leftrightarrow$ center (qualitative and quantitative traits) and south $\leftrightarrow$ west (quantitative traits) (Fig. 1).

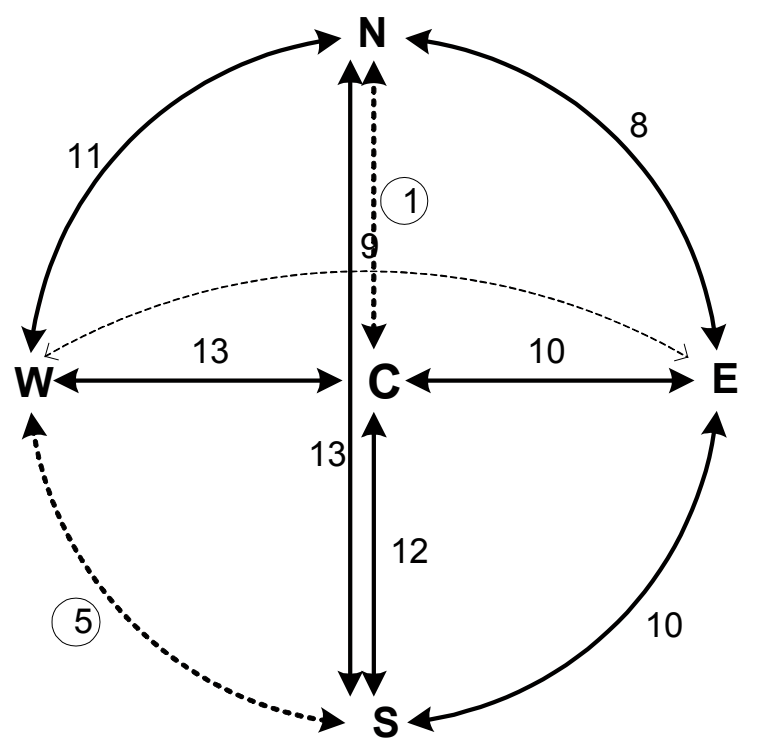

Figure 1. Zoning differences of administrative regions in Ukraine - on the basis of finger/palmar dermatoglyphics: S - south, N north, $\mathrm{W}$ - west, $\mathrm{E}$ - east, $\mathrm{C}$ - center; figures indicate the number of signs registering significant differences

Despite the unique combinations of dermatoglyphics signs which are peculiar to a particular taxonomic level of the human community, the northern and central regions demonstrate a combined similarity vis a vis a number of qualitative and quantitative traits of finger dermatoglyphics. This effect distinguishes them from the western, southern and eastern regions. Such a high affinity of finger dermatoglyphics with regard to quantitative signs also is seen in somatic healthy men from southern and western regions of Ukraine. This is distinguishable to the same from the eastern, central and northern regions.
For a selected local north-central dermatoglyphic complex, which is characteristically different from the dermatoglyphic male of the western region, the significant distinguishing features are patterns with a high intensity of crest formation (central pocket, double loop) on the I finger of the right hand, and a lack of this kind of pattern (double loop) on the V finger of the left hand, In addition, there is greater evidence of finger pattern IV on the fingers of both hands $\left(\mathrm{FRC}_{\mathrm{RN}}=16,31 \pm 6,21\right.$ and $\mathrm{FRC}_{\mathrm{RC}}=15,49 \pm 6,21$, as against $\mathrm{FRC}_{\mathrm{RW}}=13,35 \pm 6,87 ; \mathrm{FRC}_{\mathrm{LN}}=16,15 \pm 6,18$ and $\mathrm{FRC}_{\mathrm{LC}}=15,62 \pm 6,08$, as against $\left.\mathrm{FRC}_{\mathrm{LW}}=13,90 \pm 5,83\right)$. This local north-central dermatoglyphic complex is complemented by certain identifiable common features inherent to men of the northern and central region, which distinguishes them from men of the southern region. These are that the patterns of average intensity of crest formation (ulnar loop) can be seen on the II finger of the right hand, and that patterns with high intensity of crest formation (double loop) are evident on the left hand finger I. This last is accompanied by greater evidence of right hand III finger pattern $\left(\mathrm{FRC}_{\mathrm{RN}}=12,68 \pm 6,48\right.$ and $\mathrm{FRC}_{\mathrm{RC}}=11,61 \pm 6,69$, as against $\left.\mathrm{FRC}_{\mathrm{RS}}=9,128 \pm 7,058\right)$ right and I finger $\left(\mathrm{FRC}_{\mathrm{LN}}=17,75 \pm 7,97\right.$ and $\mathrm{FRC}_{\mathrm{LC}}=17,45 \pm 7,61$, as against $\left.\mathrm{FRC}_{\mathrm{LS}}=14,55 \pm 7,55\right)$ on the left hand, as well as higher values of aggregate and total comb accounts $\left(\mathrm{SRC}_{\mathrm{R} \mathrm{N}}=72,49 \pm 25,96\right.$ and $\mathrm{SRC}_{\mathrm{RC}}=71,69 \pm 24,75$, as against $\mathrm{SRC}_{\mathrm{R}}=62,53 \pm 24,38$; $\mathrm{SRC}_{\mathrm{L} \mathrm{N}}=70,89 \pm 27,40$ and $\mathrm{SRC}_{\mathrm{LC}}=70,95 \pm 25,64$, as against $\mathrm{SRC}_{\mathrm{LS}}=60,09 \pm 23,97 ; \mathrm{TRC}_{\mathrm{N}}=143,4 \pm 52,2$ and $\mathrm{TRC}_{\mathrm{C}}=142,3 \pm 49,1$, as against $\left.\mathrm{TRC}_{\mathrm{s}}=122,6 \pm 46,4\right)$. Similar commonly identifiable dermatoglyphics are evident between the north and center, and the east. Among these are the existence of a pattern of high intensity of crest formation (central pocket, double loop) on the I and V fingers of the right hand, and the IV finger of the left hand, as well as a pattern with medium intensity of crest formation (ulnar loop) on the III finger of the left hand which is accompanied by a greater intensity of pattern on the I finger of the right $\left(\mathrm{FRC}_{\mathrm{RN}}=19,28 \pm 6,84\right.$ and $\mathrm{FRC}_{\mathrm{RC}}=19,30 \pm 7,38$, as against $\left.\mathrm{FRC}_{\mathrm{RE}}=15,78 \pm 7,35\right)$, and on the I finger of the left hand $\left(\mathrm{FRC}_{\mathrm{LN}}=17,75 \pm 7,97\right.$ and $\mathrm{FRC}_{\mathrm{LC}}=17,45 \pm 7,61$, as against $\left.\mathrm{FRC}_{\mathrm{LE}}=14,80 \pm 7,05\right)$.

With regard to a local southwestern dermatoglyphic complex, common in southern and western regions, and different from the dermatoglyphics of men from eastern regions, we see a typically smaller capacitance values of pattern on the right III finger $\left(\mathrm{FRC}_{\mathrm{R}}=9,128 \pm 7,058\right.$ and $\mathrm{FRC}_{\mathrm{RW}}=10,20 \pm 6,12$, as against $\left.\mathrm{FRC}_{\mathrm{RE}}=12,60 \pm 6,29\right)$ and right IV finger $\left(\mathrm{FRC}_{\mathrm{LS}}=13,64 \pm 6,21\right.$ and $\mathrm{FRC}_{\mathrm{LW}}=13,90 \pm 5,83$, as against $\left.\mathrm{FRC}_{\mathrm{LE}}=16,38 \pm 5,16\right)$. However, regarding the left hand, we see a more pronounced asymmetry of comb account on the I finger. The local southwest dermatoglyphic complex is complemented by the identified common features inherent for men from southern and western regions, which distinguishes them from men of the central region. These include smaller capacitance values of pattern on the left II finger $\left(\mathrm{FRC}_{\mathrm{RS}}=8,83 \pm 7,97\right.$ and $\mathrm{FRC}_{\mathrm{RW}}=9,268 \pm 7,264$, as against $\left.\mathrm{FRC}_{\mathrm{RC}}=11,88 \pm 7,06\right)$, and aggregate and total comb accounts $\left(\mathrm{SRC}_{\mathrm{RS}}=62,53 \pm 24,38\right.$ and $\mathrm{SRC}_{\mathrm{R}}=64,13 \pm 24,60$, as against $\mathrm{SRC}_{\mathrm{RC}}=71,69 \pm 24,75 ; \mathrm{SRC}_{\mathrm{L} \mathrm{s}}=60,09 \pm 23,97$ $\operatorname{andSRC}_{\mathrm{LW}}=62,92 \pm 24,85$, as against $\mathrm{SRC}_{\mathrm{LC}}=70,95 \pm 25,64$; 
$\mathrm{TRC}_{\mathrm{S}}=122,6 \pm 46,4$ and $\mathrm{TRC}_{\mathrm{w}}=127,0 \pm 48,1$, as against $\left.\mathrm{TRC}_{\mathrm{C}}=142,3 \pm 49,1\right)$. The local southwestern dermatoglyphic complex includes features that distinguish men born in this region from the men of the northern region. Such features include smaller capacitance pattern values of the right III finger $\left(\mathrm{FRC}_{\mathrm{RS}}=9,128 \pm 7,058\right.$ and $\mathrm{FRC}_{\mathrm{RW}}=10,20 \pm 6,12$, as against $\left.F R C_{R N}=12,68 \pm 6,48\right)$ and the left IV finger $\left(\mathrm{FRC}_{\mathrm{RS}}=13,63 \pm 6,21\right.$ and $\mathrm{FRC}_{\mathrm{R}}=13,90 \pm 5,83$, as against $\left.\mathrm{FRC}_{\mathrm{RN}}=16,15 \pm 6,18\right)$.

This situation is explained by S.P. Segeda [5], who studied the differentiation of the Ukrainian population according to dermatoglyphics. The result of such work is that he set three variants of dermatoglyphics: south, central and north. A comparison of administrative territorial prevalence of these variants with the location of administrativeterritorial regions, reveals that in the northern administrative-territorial region, all three of Segeda's dermatoglyphic options are common, whereas in the central region, two variants are common: the central and south. Therefore, the resemblance of dermatoglyphics with regard to the central and north administrative territorial regions is apparently induced by the significant share of the central and southern variants of dermatoglyphics in the northern region. The similarity of finger/palmar dermatoglyphics by quantitative indicators in the southern and western regions also finds an explanation within the work of S.P. Segeda [5]. Herein, while the first region registers the southern variant of dermatoglyphics and the second does so though dominating north and central complexes, the similarity of dermatoglyphics of these two regions is brought about through the contribution of the dermatoglyphics of the Carpathians. This is recognized as being the southwestern dermatoglyphic branch complex of Ukraine.

It should be noted that I. G. Shyrobokov [7] interprets the presence of several dermatoglyphics complexes on Ukraine's ethnic territory as coming about as a result of the mixed composition of the present mobile population masking the original anthropological components of varied origins.

Based on an analysis of palmar dermatoglyphic indicators, several administrative-territorial regions have been identified that have minor differences between them. These are: west $\leftrightarrow$ north $\leftrightarrow$ east ( 1 sign), west $\leftrightarrow$ south $\leftrightarrow$ east ( 2 signs) and north $\leftrightarrow$ center ( 2 signs). That such indicators are noticeable, gives reason to evaluate such in these territorial limits as being genetically related. At the same time, our work found that the vector of differences on the basis of palmar dermatoglyphics passes through the central regions of Ukraine towards the west, east and south of the country, as well as west $\leftrightarrow$ east (Fig. 2).

For the palmar dermatoglyphics of the central region of Ukraine, what distinguishes it from that of the western region is characteristically the more frequent presence of a palmar pattern in the area of the hypothenar of the right hand $\left(\mathrm{Hyp}_{\mathrm{RC}}=85,5 \%\right.$, as against $\left.\mathrm{Hyp}_{\mathrm{R}}=66,2 \%\right)$ and left $\left(\mathrm{Hyp}_{\mathrm{LC}}=83,6 \%\right.$, as against $\left.\mathrm{Hyp}_{\mathrm{LW}}=69,0 \%\right)$ and in the II interdigital interval of the right hand ( $\mathrm{II}_{\mathrm{RC}}=72,1 \%$, as against $\left.\mathrm{II}_{\mathrm{RW}}=53,5 \%\right)$ and left $\left(\mathrm{II}_{\mathrm{LC}}=70,3 \%\right.$, as against $\left.\mathrm{II}_{\mathrm{LW}}=56,3 \%\right)$, as well as in the III interdigital interval of the left hand $\left(\mathrm{III}_{\mathrm{LC}}=95,8 \%\right.$, as against $\left.\mathrm{III}_{\mathrm{LW}}=88,7 \%\right)$.

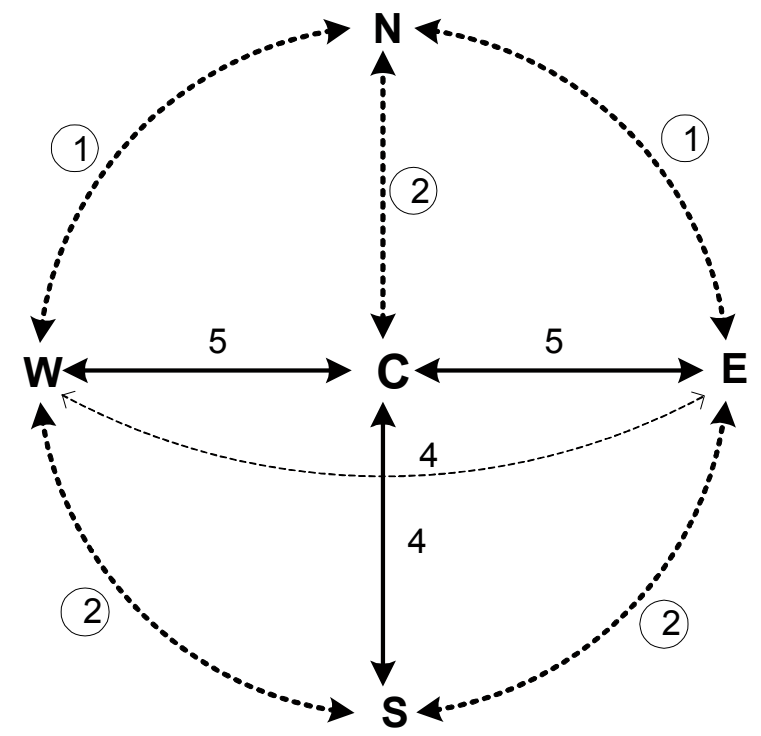

Figure 2. Zoning of differences in the administrative territorial regions of Ukraine via palmar dermatoglyphics

Noted differences in the structure of the palmar skin comb of the central region of Ukraine distinguishes this region from the eastern region. Such difference include a smaller angle value noticeable in the right hand $\left(\angle \mathrm{dat}_{\mathrm{RC}}=57,49 \pm 6,17^{\circ}\right.$, as against $\left.\angle \mathrm{dat}_{\mathrm{RE}}=59,60 \pm 6,44^{\circ}\right)$, greater Cummins index values $\left(\mathrm{IC}_{\mathrm{LC}}=8,544 \pm 2,220\right.$, as against $\mathrm{IC}_{\mathrm{LE}}=7,795 \pm 2,205$ ) and the absence (as opposed to east) of an additional three radius central axis $\left(\mathrm{t}^{\prime \prime}{ }_{\mathrm{LC}}=0\right.$, as against $\mathrm{t}_{\mathrm{LE}}{ }_{\mathrm{L}}=4,4 \%$ ) on the left hand. Other identifiers include a more frequent presence of palmar pattern in the II interdigital interval of the right hand $\left(\mathrm{II}_{\mathrm{RC}}=72,1 \%\right.$, as against $\left.\mathrm{II}_{\mathrm{RE}}=46,7 \%\right)$ and the left hand $\left(\mathrm{II}_{\mathrm{LC}}=70,3 \%\right.$, as against $\left.\mathrm{IIC}_{\mathrm{E}}=53,3 \%\right)$. Furthermore, there are marked differences with regard to the terms of asymmetry angles $\angle$ atd and $\angle$ ctd. These are characterized by the right-sided predominance of values, as opposed to the eastern region where there is a prevalence of left-sided fixed values. Moreover, this is less pronounced than in the east left-side prevalence of the $\angle$ atb values.

For the palmar dermatoglyphics of the central region of Ukraine, this is distinguishable from that of southern region due to a higher Cummins index value of the left hand $\left(\mathrm{IC}_{\mathrm{LC}}=8,544 \pm 2,220\right.$, as against $\left.\mathrm{IC}_{\mathrm{LS}}=7,766 \pm 1,722\right)$, and more frequent presence of palmar pattern in the area of the left palm thenar $\left(\operatorname{Ten}_{\mathrm{LC}}=74,5 \%\right.$, as against $\left.\operatorname{Ten}_{\mathrm{LS}}=55,3 \%\right)$, in addition to differences in the II interdigital interval of the right hand $\left(\mathrm{II}_{\mathrm{RC}}=72,1 \%\right.$, as against $\mathrm{II}_{\mathrm{R} \mathrm{S}}=51,1 \%$ ) and left $\left(\mathrm{II}_{\mathrm{LC}}=70,3 \%\right.$, as against $\left.\mathrm{IIC}_{\mathrm{S}}=53,2 \%\right)$. What is more, there are differences in the indicators of asymmetry of the Cummins index (for the men of the central regions, this characterized by a more symmetry course of main palmar lines) and a more pronounced asymmetry presence of pattern in the II interdigital interval.

With regard to the palmar dermatoglyphics of the central region of Ukraine, what distinguishes it from that of eastern region is characteristically its higher $\angle$ atd angle values in the right palm $\left(\angle \operatorname{atd}_{\mathrm{RW}}=41,35 \pm 5,46^{\circ}\right.$, as against $\left.\angle \operatorname{atd}_{\mathrm{RE}}=38,82 \pm 4,87^{\circ}\right)$ and $\angle \mathrm{atb}\left(\angle \mathrm{atb}_{\mathrm{RW}}=16,44 \pm 2,69^{\circ}\right.$, 
as against $\left.\angle \mathrm{atb}_{\mathrm{RE}}=15,24 \pm 2,47^{\circ}\right)$, smaller $\angle$ dat right palm angle value $\left(\angle \mathrm{dat}_{\mathrm{R} W}=56,90 \pm 5,74^{\circ}\right.$, as against $\angle$ dat $\left._{\mathrm{RE}}=59,60 \pm 6,44^{\circ}\right)$ and the length of the ct segment of the right palm $\left(\mathrm{ct}_{\mathrm{R} \mathrm{W}}=80,84 \pm 10,47\right.$, as against $\mathrm{ct}_{\mathrm{RE}}$ $=84,86 \pm 8,18)$. Furthermore, the $\angle$ atd and $\angle$ ctd angles in men of the western region are typically right-handed, whereas in those of the east, these are prevalently left-sided. Moreover, with regard to the cd comb account, right-sided asymmetry is more pronounced in men of the eastern region.

The ascertained palmar dermatoglyphic features in men of central administrative territorial region are far more different than that of all other regions. The discovered values essentially correspond to S.P. Segeda>s central dermatoglyphic complex [5], albeit, in terms of absolute value, these are larger, Such values are characterized by their mostly «western» combination of dermatoglyphic characteristics: medium-high Cummins index and high frequency patterns on the hypothenar. We also noted that the frequency patterns on the thenar and in the II and III interdigital spaces is also far higher. With regard to this situation, the results of geographical and correlation analysis of the dermatoglyphic system [5] point to a gradual strengthening of the southeuropeoid component from the North to the South-West, South and South-East of Ukraine.

In summary, we note that according to our data, finger dermatoglyphic signs are characterized by a more pronounced resolution, when compared with the signs of palmar dermatoglyphics. What is more, the obtained data about dermatoglyphic options according to digital signs, as distributed within the various administrative territorial regions of Ukraine, is complementary to scientific data about population differentiation of Ukraine according to S.P. Segeda's palmar dermatoglyphics [5]. Furthermore, the data obtained with regard to palmar dermatoglyphics demonstrate the ratio of complexes revealed by the aforementioned author, within the limits of the current administrative territorial regions of Ukraine.

Thus, our work has revealed certain administrative territorial peculiarities of dermatoglyphic complex within somatic-healthy men. This illustrates the complex history of the formation of the Ukrainian population, and it reflects the migration of population from the east to areas that are north and south of the country, and the preservation of Ukrainian authenticity in the center of the country, with a shift towards the north.

\section{CONCLUSION}

In conclusion:

1. The North and Central and South and West administrative territorial regions of Ukraine are characterized by high phenotypological affinity of complex finger dermatoglyphic signs within these administrative boundaries. Herein, the greatest variability in the quality of such signs is detectable between the Centre and East, North and South, East and South; while in quantitative terms, it is so between the Centre and the West, and Centre and South.
2. The North and Central, North and West, North and East, South and West, South and East administrative territorial regions of Ukraine are characterized by high phenotypological uniformity with regard to complex palmar dermatoglyphic signs. The greatest differences in terms of palmar dermatoglyphics are noticeable between the Centre and the East, the Centre and West, the Centre and South, and the East and West.

3. A differentiation of local population is made possible through the following high taxonomic values: the types of patterns exhibiting high intensity of crest formation, the pattern capacity, hypothenar and thenar patterns, II and III interdigital intervals, the $\angle$ atd, $\angle$ atb, $\angle$ dat angles, the Cummins index, the presence of an additional threeaxis radius, and the length of the ct segment.

The identified administrative-territorial peculiarities of the dermatoglyphic complex of somatic-healthy men illustrate the complex history of the formation of the Ukrainian population. It reflects the migration of population from the east to areas that are north and south of the country, and the preservation of Ukrainian authenticity in the center of the country with a shift to the north. This is so despite the often tragic history of famine and war within this great nation.

\section{REFERENCES}

1. Cummins H., Midlo Ch. Finger Prints, Palms and Soles. An Introduction to Dermatoglyphics. Philadelphia, 300, 1961.

2. Stosljević M, Adamović M. Dermatoglyphic characteristics of digitopalmar complex in autistic boys in Serbia. Vojnosanit Pregled. 70, 4, 2013.

3. Norris M. Durham, Kathleen M. Fox, Chris C. Plato. The State of Dermatoglyphics: The Science of Finger and Palm Prints Edwin Mellen Press, 365, 2011.

4. Khit G.L., Shirobokov I.G., Slavolyubova I.A. Dermatoglyphics in anthropology. St. Petersburg: Nestor history, 376, 2013.

5. Segeda S.P. Anthropological composition of the Ukrainian people: ethnogenetic aspect. Publishing house named after Olena Teliha, 256, 2001.

6. Shinkaruk-Dykovytska M.M. Medical and social factors of living conditionsof somatic healthy men from various natural and administrative regions of Ukraine. Biomedical and biosocial anthropology, 19, 2012.

7. Shirobokov I.G. Anthropological structure of Karel according to the data dermatoglyphics. Microevolutionary processes in human populations, St. Petersburg: MAE RAS, 2009. 